\title{
A Cross Sectional Study of the Knowledge and Practice of Self-Breast Examination among Market Women at the Makola Shopping Mall, Accra, Ghana
}

\author{
Elorm Kudzawu',2, Francis Agbokey3, Collins S. K. Ahorlu4* \\ ${ }^{1}$ Korle-Bu Teaching Hospital, Accra, Ghana \\ ${ }^{2}$ School of Public Health, University of Ghana, Accra, Ghana \\ ${ }^{3}$ Kintampo Health Research Centre, Ghana Health Service, Kintampo, Ghana \\ ${ }^{4}$ Noguchi Memorial Institute for Medical Research, University of Ghana, Accra, Ghana \\ Email: elormbeauty@yahoo.com,agbokey2000@yahoo.com, *cahorlu@noguchi.ug.edu.gh
}

Received 7 May 2016; accepted 25 June 2016; published 28 June 2016

Copyright (C) 2016 by authors and Scientific Research Publishing Inc.

This work is licensed under the Creative Commons Attribution International License (CC BY). http://creativecommons.org/licenses/by/4.0/

(c) (i) Open Access

\section{Abstract}

Background: Breast cancer is one of the most common cancers in women worldwide. With an estimated incidence of $1,676,633$ with 521,817 deaths in the year 2012, the figure is expected to hit the 82.5 millionth mark by 2015 . Breast cancer screening is reported to be extremely low in most low-middle income countries like Ghana. This study was to determine the knowledge and practices of self-breast examination among market women at Makola Shopping Mall in Accra, Ghana. Methods: The study was conducted at the Makola Shopping Mall in Accra among women above the age of 20 years who owned a store and sell at the mall. Data were collected using mixed method involving in-depth interviews and questionnaire survey. Random samples of 170 participants were selected from a population of 400 for the quantitative survey. A total of eight in-depth interviews were conducted to generate qualitative data to complement the survey data. Results: Majority (60\%) of the respondents were between the ages of 20 - 40 years. There's a high literacy rate among the participants. Though awareness of self-breast examination was very high (93\%), only $27 \%$ practiced self-breast examination in line with the recommended one week period after menses due to lack of knowledge of the basic skills to do self-breast examination. Conclusion: In view of the lack of knowledge resulting in non-performance of self-breast examination, continuous education on breast cancer screening should be given to the women to enable them acquire the skills of performing self-breast examination to promote early detection of the disease.

\footnotetext{
${ }^{*}$ Corresponding author.
} 


\title{
Keywords
}

\author{
Breast Cancer, Self Breast Examination, Knowledge, Practices, Prevention, Treatment, Accra, \\ Ghana
}

\section{Introduction}

Breast cancer is a tumour that starts from the cells of the breast tissue [1]. Breast lump can be benign or malignant; the latter can be life-threatening because they are cancerous and can invade surrounding tissues or metastasized to other parts of the body through the lymphatic system [2]. Breast cancer affects both sexes but the rate is more common in women than in men. It is one of the most commonly found cancers in women worldwide and its morbidity and mortality are of great public health concern worldwide [3]-[7]. The world breast cancer incidence was estimated to be 1,676,633 and 521,817 mortality in the year 2012 [8]. Breast cancer accounted for $14 \%$ of all female cancers worldwide [4] [5]. Annually, about one million new cases of female breast cancers are diagnosed worldwide [9]-[12]. World Health Organisation (2008) estimated that by the year 2015, 82.5 million women will die of breast cancer [13] and by 2020 , approximately $70 \%$ of new cancer cases will occur in developing countries, and a substantial amount of them are likely to be breast cancer [14].

Globocan has estimated the 2012 breast cancer incidence for Africa to be 133,890 out of which 63,160 resulted in mortality for women [8]. In sub-Saharan Africa, 23.5 per 100,000 cases of breast cancer were recorded in 2008 in women aged 15 years and above and an estimated 35,427 resulted in mortality [15]. It has been noted that there is a demographic change in incidence and mortality associated with breast cancer, especially in the developing countries, where previously, lower incidence and mortality were recorded [4]. Also more breast cancer cases are being recorded in Africa due to changes in lifestyles [16] [17]. The lifestyles of most Africans are now becoming more sedentary than the formal agrarian system they used to operate [17]. Compared to the West, there are higher mortalities associated with breast cancer in Africa or among Africans [18]. The days of low breast cancer incidence rates enjoyed by developing countries in Africa have long passed [4].

In Ghana, the percentage of women being affected by breast cancer is not known [19]. This is because national data on breast cancer incidence are lacking due to a lack of cancer register in the country [20] [21]. However, institutional data from Accra and Kumasi suggested a high incidence and mortality of breast cancer in the country [19] [22]. In Ghana, it was estimated by IARC in 2012 that breast cancer constituted 2260 (24.2\%) of all cancer cases with a mortality of $1021(18.5 \%)$ [8]. Ghana has an estimated breast cancer incidence of $0.68 \%$ and accounted for $34 \%$ of all deaths among women with a disease burden of $31 \%$, which is projected to increase due to aging, rapid urbanisation and unhealthy lifestyle [20].

Breast cancer is now a disease for the younger population in the East and Gulf regions as compared to the West [10] [23]. Breast cancer is being diagnosed at younger age among African-American women [18]. In Ghana, breast cancer is affecting relatively younger population with women as young as 20 years affected compared to Europe and America [19] [21] [22].

Breast cancer is the second commonest cancer after cervical cancer among Ghanaian women and it forms $40 \%$ of all female cancers. In Ghana, breast cancer is a leading malignancy as it accounts for $15.4 \%$ of all cancer cases and this is on the increase. This calls for an immediate intervention to curb the disease. In 1996, 12.8\% of all admission for malignant neoplasm at the Korle-Bu Teaching Hospital (KBTH) was breast cancer [19]. Even though breast cancer awareness has increased over the years in Ghana, about 50\% or more of breast cancer patients report to KBTH when the disease is advanced [19].

Morbidities and mortalities associated with breast cancer are high in developing countries due to late reporting for health care and lack of screening methods. Late reporting for health care is associated with local beliefs and misconceptions surrounding breast cancer; especially among Africans. These beliefs include religiosity, spirituality, and fatalistic beliefs [3] [24] [25]. Changes in breast are mostly detected by the women themselves but they often report for health care several months after detecting these changes [19] [21]. In most cases, the breast lumps are detected often accidentally either during bathing or dressing [26]. It is stated that, breast cancer awareness and understanding is low among the general population in Africa [27].

This calls for preventive measures to fight this menace globally, especially in the developing countries where 
access to mammography and clinical breast examination is limited or virtually inaccessible. The unavailability of mammography and Clinical Breast Examination (CBE) calls for an extensive education on the usefulness of SBE [28], which can help in early case detection and management of the disease and thereby lead to the reduction of associated morbidity and mortality among women [29] [30]. Self-breast examination is the technique where a woman examines her own breast. It also helps them to detect any change in their breasts at an early stage [31]. Self-breast examination is inexpensive, non-invasive, and does not require much time and physical energy. It is also very simple and no professional help is needed [31]. In Ghana, Self-breast examination (SBE) has been adopted as an early detection screening tool for breast cancer. The national Strategy for Cancer Control in Ghana (2012-2016) proposed that breast cancer screening should be taught in school as a means of creating breast cancer awareness to promote early detection of the disease. This education was to starts at age 16 in all schools in the country. Sadly however, this strategy is yet to be implemented [20].

Breast cancer screening is extremely low in most low- middle income countries like Ghana and was estimated to be less than 5\% in 2000-2003 [32]. Early detection of breast cancer is the best way to control the disease [33] and reduction in the mortality associated with the disease is done through screening methods such as SBE, CBE and mammography or imaging study [9]. Self-breast examination is the only realistic approach to early detection of breast cancer in the developing countries [11]. Mostly breast cancer is detected by the women themselves, through periodic practice of SBE [11] [34]. Some researchers have observed that, SBE is the most important diagnostic tool for the early diagnosis of breast cancer [35]. It has been reported that SBE places a psychological responsibility of good health practice on the individual [36]. Some experts have argued that a decrease in SBE will result in a decrease in early detection of breast cancer and vice versa [4].

In the Scandinavian countries there is a decrease in breast cancer mortality by $31 \%$ after seven years of performing SBE correctly among women aged between 40 and 70 years [31]. This was because; breast cancer cases were detected early. Self-breast examination has the potential to advance the diagnosis of breast cancer without the expensive mammography facility. Breast tumours detected in women who perform SBE regularly are smaller in size on an average compared to those detected in women who do not perform SBE. This is because women who regularly perform SBE are more likely to detect changes in their breast at the initial stages [37].

Accessing breast cancer preventive measure is facing several challenges such as financial and gender barriers. Therefore, there is the need to emphasise breast cancer prevention through the use of SBE which is simple, inexpensive and non-invasive [15]. Although SBE is said to be useful in early case detection of breast cancer, most women do not examine their breasts and a great proportion of women do not know how to perform SBE [31] [33]. However, adapting a screening method depends on several factors including religious beliefs, attitude of physicians or primary care providers, and motivation by the community nurses [4] [38]. It has been reported that employment status and availability of social support have an effect on improving the breast health because employed woman can afford health care and other advanced forms of breast screening methods such as mammogram, while the unemployed women have time to regularly perform SBE but cannot afford other more reliable breast screening methods [34] [39].

A survey in the West in the 1990's indicated that despite high level of awareness created about monthly performance of SBE, only a small (21\%) minority of women ever performed it regularly even among female doctors in America for several reasons [40]. In Egypt, only 5\% of the female university students have knowledge in SBE and more than $90 \%$ of the participants never practice SBE [35]. A study among high school students in Turkey shows that they do not have sufficient knowledge on SBE and its performance [41]. Studies in Iran have reported that, Iranian women have inadequate knowledge on SBE [11] [42], however a study from Iraq stated otherwise. Indicating that $90.9 \%$ of the study participants have heard of SBE and $48.3 \%$ practise it [33]. Other studies reported that only $6 \%$ to $17 \%$ of participants were practising SBE regularly [11] [42]. Lower levels of knowledge and practice of SBE was also recorded among Malaysian women with a history of breast cancer [12]. A study in the Buea Community in Cameroon indicated that, about three-quarters of the population reported having heard of SBE but less than a quarter were practising it, with $35 \%$ and $12.5 \%$ performing it monthly and six-monthly respectively [15].

In Ghana as in other developing countries where there are infrastructural problems, especially in the health sector, it is expected that more preventive measures should be adopted. A study conducted in Kumasi on breast cancer awareness among nurses reported that more than half (54\%) of the respondents were knowledgeable about SBE and $72 \%$ of them practice SBE. Though most nurses use SBE as their screening method for breast cancer, most of them do not practise it regularly as recommended [22]. However, knowledge deficit in the 
screening methods for breast cancer such as SBE in Ghana was reported [16].

Self-breast examination is recommended as one of the overall health promotion concepts for breast cancer [4]. Several reasons have been associated with the non-performance of SBE. Some of them include forgetfulness [43], lack or inadequate knowledge on SBE and practice [44] false assurance when cancer is present, false positive results, anxiety of finding something suspicious and being subjected to unnecessary medical investigation. This study is designed to determine the knowledge and practices of self-breast examination among market women at Makola shopping mall in Accra.

\section{Methods}

\section{Study Design}

Data were collected using mixed method involving in-depth interviews (IDI) and questionnaire survey. The study was conducted at the Makola Shopping Mall in Accra. The Mall is located in the Ashiedu Keteke SubMetropolitan Area of the Accra Metropolis, in the central business centre. There are about 400 traders in the Mall with majority of them being women, trading in cloths from various manufacturers. Market women above the age of 20 years who owned a store and sell in the market were included in the study. A total of eight in-depth interviews (IDI) were conducted to generate qualitative data to complement the survey data. A random sample of 170 participants was selected for the survey, representing over $50 \%$ of the women who met the inclusion criteria.

Quantitative data were analysed using Statistical Package for Social Science Version 20 (SPSS version 20). Frequencies, proportions and percentages were used to represent findings descriptively. Qualitative data from the field were transcribed verbatim into Microsoft Word for windows. Manual colour coding was done and similar responses were grouped under specific themes. Content analysis was done based on emerging themes and sub-themes. The descriptive narratives supported by illustrative quotes were presented in the results using pseudonyms.

The study protocol and all data collection tools were reviewed and approved by the Ghana Health Service Ethical Review Committee and was given a reference number GHS/ERC60/04/24. The study objectives were explained to the leadership of the market women, management of the Mall and the individual participants, after which a written informed consent was obtained from every participant before data collection.

\section{Results}

We found that $102(60 \%)$ of the respondents were between the ages of $20-40$ years, (82\%) of the respondent were Christians and only $4(2 \%)$ were traditional believers. The Akans and Gas were the dominant ethnic groups working in the Mall, representing $38 \%$ and $33 \%$ respectively and $74(44 \%)$ of them were married. About 50 (29\%), of the respondent have attained either Senior High School (SHS) or Post Secondary School levels education. Of the remaining, 70 (42\%) attained either tertiary 21 (12\%), Junior High School (JHS) 31 (18\%), Primary $12(7 \%)$ and no education $6(4 \%)$.

Breast cancer awareness was very high (88\%) among respondents. Even higher among respondents was self-breast examination, $158(93 \%)$. Their main sources of information on breast cancer were from the electronic media, Radio (74\%) and Television (71\%). This was same for self breast examination radio (77\%) and television (71\%). The high level of awareness on SBE was confirmed during in-depth interview (IDI) sessions, where the media and health workers were frequently mentioned as the sources of information for SBE, with some participants mentioning names of the presenters of such programmes. This position is represented in the narratives below;

I heard it when I went to Trust Hospital for the Well Woman Clinic... from my mother's friend who is a community nurse, also from a female doctor on Television (Akua, 49 years old, IDI).

Yes I have heard of SBE before. People came to our church and talked about it (Mary 68 years old, IDI).

Out of 140 women who were aware of the self-breast examination, 38 (27\%) do not practise SBE. Out of the 38 respondents who reported non performance of SBE, $24 \%$ of them said they did not know how to do it and another $30 \%$ claimed it was not necessary.

The younger (less than 40 years) ladies stated they do it after their menses or a week after. Thus, $29 \%$ of the women said they usually do self breast examination just after their menstrual period and $28 \%$ did it any day in 
the month. Most of the respondents stated that SBE is a means of examining the breast for any change and they performed it regularly. However, few started examining the breast in a circular motion, starting from the armpit. However, those who were in their menopause mentioned that they did it anytime they were less busy. The narratives below represent how SBE is done by respondents;

I heard on health talk programme that, you use your finger tips to examine the breast. If there is any lump in it you report it (Maama, 62 years old).

I press my breast anytime am less busy either sitting or lying in bed (when am not feeling sleepy) (Mary, 68 years old, IDI).

Like you will lie down, you lie flat and you use hand to press your breast if you feel boil in the breast or pain in the breast then you must know that you are getting it small. I have never done it before but sometimes when am less busy, I just press my breast. I do not do it (SBE) because, I know my breast and I do not have any problem with my breast (Zulaya, 30 years old, IDI).

Respondents who did not perform SBE gave several reasons for not doing it and prominent among the reasons were lack of knowledge on how to do it and their religious faith. These positions were represented in the following narratives:

I know you lie flat, put your arm in the $U$ or $V$ shape and examine the breast (move round the breast). I know there is a way (posture) to do it but I never do it. Maybe I am just being stubborn... I think it is not necessary. I also do not do it because am not getting how to do it/not conversant with the skill. I know it is good to do it but it is me. ...By faith I won't get breast cancer, that is why I don't do it (Akua, 49 years old).

...I do not know which of the techniques is correct... lying flat on my back, standing in front of the mirror and sitting. I do it in my own way - I do it anyhow, I press my breast as and when it is necessary thus when I have a pain or feel something unusual in it (Theresa, 34 years old, IDI).

Some of the respondents intimated that there is not much education on breast cancer in Ghana, compared to STIs, hence their inability to perform SBE and requested more education on breast cancer and SBE.

I wish I have more knowledge on what to look for and how to do it well. I think health workers and minister of health should teach women how to do SBE. It is our health and we need to champion it (Theresa, 34 years old, IDI).

I also think education on it is not being happed that is not informing me. Last week there was a full page on guinea worm but it is not done for breast cancer. Women... we hold the country. ...there is the need for extensive education on it. We should get some organisations that should be sponsoring it. When it comes to football, look at the craze with which people support it. Increasing our devotion and support for sport supersedes that of our health. I must commend Vodafone and Airtel for what they are doing to the vulnerable when it comes to their health needs. Organisations that are headed by women should campaign and champion our health. We need to do it for ourselves (Akua, 49 years old, IDI).

Various positions were used to perform SBE among respondents and the commonest one reported was lying down with one hand under the head (68\%). These positions were confirmed during the IDI as represented in the narratives below;

A female doctor said that, as a lady after your menses, you can stand in front of the mirror, raised one hand and check your breast for any change and this is how I usually do it (Hajia, 37 years old, IDI).

I do SBE by sitting down and use my finger tips to press the breast (Maama 62, years old, IDI).

...I do not know which of the techniques is correct (lying flat, standing in front of the mirror or sitting) but I usually do it in my own way- depending on which of the methods come into mind. I do it anyhow (Theresa, 34 years old).

A respondent stated that she used more than one technique; either by sitting or lying. Sometimes when am there sitting, I press my breast to see if there is something there. I do it when lying down in bed (Zulaya, 30 year, IDI).

One of the respondents was of the view that a woman can also let her partner/husband examine her breasts. ...You can also let your partner examine your breast for you since he knows your breast quite well (Hajia, 37 years old, IDI). 
Lump (87.6\%) and pain (20\%) in the breast were the commonest warning signs that women look for when performing Self-Breast examination. This position was supported by the following representative narrative from IDI respondents;

...I press my breast as and when it is necessary thus when I have a pain or feel something unusual in it. I cannot tell how many times I do it in a month; I do it per the situation am in. I do not have any day/date for doing it, as and when it is necessary; I do it my own way. I think am not keen on doing it because I seem not to get the theory right. I wish to know which technique is good and how to do it best. Seriously, apart from the lump and pain I look for when pressing my breast, I wish I have more knowledge on what to look for and how to do it well (Theresa, 34 years old, IDI).

The majority (68\%) performed SBE once in a month, $13 \%$ anytime they remembered to do so. However, qualitative data suggests that some do over- performed SBE as recommended. Some said they did it when they suspected some warning signs of breast cancer.

Anytime I feel pains at the tip of the breast, I do it. I do it once in a while; this is because I do not feel any pain in the breast anymore. If the pain were to be there, it will alert me to do it and I will do it as often as I can, if I find something not normal with my breast I do it more than once in a day. Also I do not think breast cancer is all that much problem in Ghana unlike HIV/AIDS. Many people in Ghana is not suffering of it like the STDs. It is not problematic (Maama, 62 years old, IDI).

It came to light during in-depth interviews that respondents who had burning sensation in their armpit, pain in the breast or the nipple performed SBE very often and this position is captured in the narrative below:

I do it very often because am having burning sensation in my armpit or if I have any pain or anything unusual in the breast and I want to be sure if it is a boil/mango-like something there (Mary, 68 years old, IDI).

On the other hand those who experience no pain in the armpit, breast or the nipple performed it very rarely as reported by a 38 years old lady in the following narrative:

...I try to do it but not often because I do not have any medical challenge. I feel no pain in breast or armpit, so I do SBE but not every month as I was told... (Frances, 38 years old, IDI).

Out of the 25 respondents who did examine their breasts more than once in a month using any of the techniques, $6(24 \%)$ of them did so because they wanted to detect breast cancer at an early stage when it happens and another $6(24 \%)$ did so for fear of dying from the disease without realising it.

\section{Discussion}

Findings from this study are similar to what were observed in other studies among market women in Iran and Nigeria [4] [11], where majority of the respondents were below the age of 40 years and were married with secondary and post-secondary education.

The success of most disease control efforts depend largely on the awareness of the population at risk and breast cancer is no different. Breast cancer awareness among respondents in this study was very high (88\%) and this could serve as an entry point to increase breast cancer education especially on the need for frequent selfbreast examination so as to pick early suspected cases for self-referral to the clinic for assessment and diagnosis. The high level of awareness confirmed what was reported among Market Women in Nigeria, where $78 \%$ of the market women were aware of breast cancer [4]. However, these findings contradict what was reported among students in Turkey and Nigeria, where low levels of awareness were reported [41] [45] [46].

A significant finding of this study was the lack of knowledge on local names/terms used to describe breast cancer among a portion of the respondents and this makes the description of the disease seems abstract to these respondents. Thus, there is a need for more education on the local descriptions of the clinical presentations of the disease as well as suspected signs and symptoms to make it easy for the general population to appropriately conceptualize the disease in practical terms. It is hoped that if respondents could conceptualize breast cancer in more practical terms, they may be encouraged to perform SBE.

Since the media, especially radio and television were the two most common sources of information on the disease, they must be exploited by taking advantage of popular programmes to have slots for discussing issues 
relating to breast cancer. Unlike Nigeria, where the most common sources of breast cancer information among market women were the elders, neighbours and friends [46], this study found that the radio and television were the most common sources of information on breast cancer and this confirmed what was reported from Iraq and Turkey [33] [47]-[49], that the media, both virtual and audio were prominent sources of breast cancer awareness. Thus, the high level of breast cancer awareness among study participants could be attributed to the proliferation of private television and radio stations in the country, most of which have programmes in the local languages and this attracts large listening audience. The difference in the levels of knowledge among nurses studied in Kumasi where only 54\% were knowledgeable and the current study could be explained by the breast cancer related radio programmes being organized in local languages which are accessible to the market women because they have time to listen to the radio while sitting in their shops. Nurses often do not have time to listen to some of these local language programmes and even if they do, they may prefer an English language programmes. To take advantage of this will require that programme implementers provide resource persons to help these media houses to develop relevant and appropriate programme contents that will not mislead the people but instead educate them on the disease.

Just like breast cancer awareness, 158(93\%) of the market women in Makola Shopping Mall were aware of SBE through the media (radio and television) and $73 \%$ had knowledge on how to perform SBE. This was in line with what was reported among female university students at a Presbyterian University College in Ghana, where $95 \%$ of the respondents were aware of SBE and $80 \%$ have a good knowledge on how to perform it [50]. Other studies also made similar findings [33] [51] [52].

Though, in our study, only $14 \%$ of respondents performed SBE a week after their menses, as recommended, it was encouraging to note that majority $(64 \%)$ of the respondents perform SBE once in a month irrespective of the time of the month. This suggests that it is possible for market women at the Makola Mall to perform SBE a week after their menses and need to be educated on the importance of the timing to encourage them to get it right. Our finding differ from what was reported from Nigeria, where high levels of awareness on SBE were reported among market women [46] and health workers [22] [53] but that did not translate to high performance rate. Our finding also disagrees with the result among Jordanian nurses, where most of the respondents reported performing SBE but less than one out of four performed it regularly as recommended [54]. High levels of awareness on SBE in Western countries were reported in the 1990s; however, this awareness did not translate into the performance of SBE as a small minority of women reportedly examined their breast once in a month [30] [46].

\section{Conclusion}

There was high level of awareness on breast cancer and self-breast examination among market women in the Makola Shopping Mall. Most of the respondents got to know about breast cancer and self-breast examination through the media both visual (television) and audio (radio). Although there was high level of awareness on SBE, majority of the respondents performed SBE anytime in the month, which was contrary to the recommended period of a week after menses. Some of the respondents blamed their non-performance of SBE on lack of knowledge/skills on how to perform it. The fact that most respondents who did not perform SBE said it was due to lack of knowledge on how to perform it called for continuous education on breast cancer in general but self-breast examination in particular to promote SBE among market women in the Makola Shopping Mall in Accra. The promotional message should address the various appropriate positions and timing for performing self-breast examination as a way to enhance early diagnosis and treatment of the disease to reduce its related complications. One major weakness of the study was that it was limited to women aged above 20 years and this would be taken into consideration in future studies.

\section{Acknowledgements}

We express our profound gratitude to all the women in Makola Shopping Mall who graciously participated in this study but for their willingness to provide information there will have been no study. We also thank the leadership of the Makola traders Association for granting us access to their members and helping us to locate and interview all respondents.

\section{Conflict of Interest}

The authors declare that they have no competing interests. 


\section{Authors' Contributions}

EK participated in the study design, data collection, data analysis, writing of the manuscript and approved of it for publication. FA participated in data collection, data analysis, reviewed the manuscripts and approved it for publication. CSKA participated in the study design, data analysis, writing of the manuscript and approved of it for publication.

\section{Authors' Information}

EK (Bachelor of Arts in Nursing and Psychology and Masters in Applied Health Social Sciences): Is a Senior Nursing Officer at the Korle-Bu, Teaching Hospital, Accra, Ghana and at the time of this study she was a masters student at the School of Public Health, University of Ghana, Legon.

FA (Bachelor of Education in Psychology and Masters in Applied Health Social Sciences) Is a Research Officer at the Kintampo Health Research Centre, Ghana.

CSKA (BA Sociology, MA Sociology and PhD in Epidemiology): Is a Senior Research Fellow at the Noguchi Memorial Institute for Medical Research, University of Ghana, Legon, Accra, Ghana.

\section{References}

[1] Ali, S. and Coombes, R.C. (2002) Endocrine-Responsive Breast Cancer and Strategies for Combating Resistance. $\mathrm{Na}$ ture Reviews Cancer, 2, 101-112. http://dx.doi.org/10.1038/nrc721

[2] Peepliwal, A.K. and Tandale, P. (2013) Breast Cancer in India: Etiology, Diagnosis and Therapy. Research \& Reviews: Journal of Medical and Health Sciences, 2, 31-42.

[3] Gullatte, M., Phillips, J. and Gibson, L. (2006) Factors Associated with Delays in Screening of Self-Detected Breast Changes in African-American Women. Journal of National Black Nurses' Association: JNBNA, 17, 45-50.

[4] Obaji, N.C., Elom, H.A., Agwu, U.M., Nwigwe, C.G., Ezeonu, P.O. and Umeora, O.U.J. (2013) Awareness and Practice of Breast Self-Examination among Market Women in Abakaliki, South East Nigeria. Annals of Medical and Health Sciences Research, 3, 7-12. http://dx.doi.org/10.4103/2141-9248.109457

[5] World Health Organisation (2011) Breast Cancer: Prevention and Control.

[6] Clegg Lamptey, J., Dakubo, J. and Attobra, Y. (2009) During Treatment in Ghana? A Pilot Study. Ghana Medical Journal, $\mathbf{4 3}, 3$.

[7] Ibrahim, N.A. and Odusanya, O.O. (2009) Knowledge of Risk Factors, Beliefs and Practices of Female Healthcare Professionals towards Breast Cancer in a Tertiary Institution in Lagos, Nigeria. BMC Cancer, 9, 76. http://dx.doi.org/10.1186/1471-2407-9-76

[8] International Agency for Research on Cancer: Globocan (2012) Estimated Cancer Incidence, Mortality and Prevalence Worldwide in 2012. Accessed 29 December 2013. http://globocan.iarc.fr/Pages/fact sheets population.aspx

[9] Adetifa, F.A. and Ojikutu, R.K. (2009) Prevalence and Trends in Breast Cancer in Lagos State, Nigeria. An International Multi-Disciplinary Journal, Ethiopia, 3, 1-15.

[10] Radi, S.M. (2013) Breast Cancer Awareness among Saudi Females in Jeddah. Asian Pacific Journal of Cancer Prevention, 14, 4307-4312. http://dx.doi.org/10.7314/APJCP.2013.14.7.4307

[11] Montazeri, A., Vahdaninia, M., Harirchi, I., Harirchi, A.M., Sajadian, A., Khaleghi, F., et al. (2008) Breast Cancer in Iran: Need for Greater Women Awareness of Warning Signs and Effective Screening Methods. Asia Pacific Family Medicine, 7, 6. http://dx.doi.org/10.1186/1447-056X-7-6

[12] Loh, S.Y. and Chew, S. (2011) Awareness and Practice of Breast Self Examination among Malaysian Women with Breast Cancer. Asian Pacific Journal of Cancer Prevention, 12, 199-202.

[13] Guvenc, I., Guvenc, G., Tastan, S. and Akyuz, A. (2012) Identifying Women's Knowledge about Risk Factors of Breast Cancer and Reasons for Having Mammography. Asian Pacific Journal of Cancer Prevention, 13, 4191-4197. http://dx.doi.org/10.7314/APJCP.2012.13.8.4191

[14] Fregene, A. and Newman, L.A. (2005) Breast Cancer in Sub-Saharan Africa: How Does It Relate to Breast Cancer in African-American Women? American Cancer Society, 103, 1540-1550. http://dx.doi.org/10.1002/cncr.20978

[15] Bi Suh, M.A., Atashili, J., Fuh, E.A. and Eta, V.A. (2012) Breast Self Examination and Breast Cancer Awareness in Women in Developing Countries: As Survey of Women in Buea, Cameroon. BioMed Central, 5, 1-6.

[16] Opoku, S.Y., Benwell, M. and Yarney, J. (2012) Knowledge, Attitudes, Beliefs, Behaviour and Breast Cancer Screening Practices in Ghana, West Africa. The Pan African Medical Journal, 11, 28. 
[17] Key, T.J., Verkasalo, P.K. and Banks, E. (2001) Epidemiology of Breast Cancer. The Lancet Oncology, 2, $133-140$. http://dx.doi.org/10.1016/S1470-2045(00)00254-0

[18] Stark, A., Kleer, C.G., Martin, I., Awuah, B., Nsiah-Asare, A., Takyi, V., et al. (2010) African Ancestry and Higher Prevalence of Triple-Negative Breast Cancer. Cancer, 116, 4926-4932. http://dx.doi.org/10.1002/cncr.25276

[19] Clegg-Lamptey, J.N.A. and Hodasi, W.M. (2007) A Study of Breast Cancer in Korle-Bu Teaching Hospital: Assessing the Impact of Health Education. Ghana Medical Journal, 41, 72-77.

[20] Ministry of Health (2011) National Strategy for Cancer Control in Ghana, 2012-2016. 1-32.

[21] Ohene-Yeboah, M. and Amaning, E.P. (2008) Spectrum of Complaints Presented at a Specialist Breast Clinic in Kumasi, Ghana. Ghana Medical Journal, 42, 110-113.

[22] Ohene-Yeboah, M., Adofo, K. and Akpaloo, M. (2013) Breast Cancer Awareness among Nurses in Kumasi Ghana: Knowledge, Attitudes and Practice. Postgraduate Medical Journal of Ghana, 2, 1-7.

[23] Dahlui, M., Gan, D.E.H., Taib, N.A. and Lim, J.N.W. (2013) Breast Screening and Health Issues among Rural Females in Malaysia: How Much Do They Know and Practice? Preventive Medicine, 57, S18-S20.

[24] Lannin, D.R., Mathews, H.F., Mitchell, J., Swanson, M.S., Swanson, F.H. and Edwards, M.S. (1998) Influence of Socioeconomic and Cultural Factors on Racial Differences in Late-Stage Presentation of Breast Cancer. JAMA: The Journal of the American Medical Association, 279, 1801-1807. http://dx.doi.org/10.1001/jama.279.22.1801

[25] McMenamin, M., Barry, H., Lennon, A.M., Purcell, H., Baum, M., Keegan, D., et al. (2005) A Survey of Breast Cancer Awareness and Knowledge in a Western Population: Lots of Light but Little Illumination. European Journal of Cancer, 41, 393-397. http://dx.doi.org/10.1016/j.ejca.2004.11.015

[26] Larkin, M. (2001) Breast Self Examination Does More Harm than Good, Says Task Force (Abstract). The Lancet, 357, 2109-2110. http://dx.doi.org/10.1016/S0140-6736(00)05238-7

[27] Ohaeri, J., Campbell, O., Ilesanmi, A. and Ohaeri, B. (1998) The Opinion of Caregivers of Some Women with Breast and Cervical Cancer on Aspects of the Disease. West African Journal of Medicine, 18, 6-12.

[28] Clegg-Lamptey, J., Dakubo, J. and Attobra, Y. (2009) Why Do Breast Cancer Patients Report Late or Abscond during Treatment in Ghana? A Pilot Study. Ghana Medical Journal, 43, 127-131.

[29] Baig, M., Subramaniam, V., Chandrasegar, A. and Khan, T. (2011) A Population Based Survey on Knowledge and Awareness of Breast Cancer in the Suburban Females of Sungai Petani, Kedah, Malaysia. International Journal of Collaborative Research on Internal Medicine \& Public Health, 3, 670-679.

[30] Austin, L.T., McNally, M.J. and Stewart, D.E. (2002) Breast and Cervical Cancer Screening in Hispanic Women: A Literature Review Using the Health Belief Model. Women's Health Issues, 12, 112-128. http://dx.doi.org/10.1016/S1049-3867(02)00132-9

[31] Alsaif, A.A. (2004) Breast Self-Examination among Saudi Female Nursing Students in Saudi Arabia. Saudi Medical Journal, 25, 1574-1578.

[32] World Health Statistics (2008) Breast Cancer Mortality and Screening. 21-23.

[33] Alwan, N.A., Al-Diwan, J.K., Wafa'M, A.-A. and Eliessa, R.A. (2012) Knowledge, Attitude \& Practice towards Breast Cancer \& Breast Self Examination in Kirkuk University, Iraq. Asian Pacific Journal of Reproduction, 1, 308-311. http://dx.doi.org/10.1016/S2305-0500(13)60098-6

[34] Malak, A., Bektash, M., Turgay, A., Tuna, A. and Ekti, R. (2009) Effects of Peer Education, Social Support and Self Esteem on Breast Self Examination Performance and Knowledge Level. Asian Pacific Journal of Cancer Prevention, 10, 605-608.

[35] Salama, H., Elsebai, N., Abdelfatah, F., Shoma, A. and Elshamy, K. (2013) Effects of Peer Education on the Knowledge of Breast Cancer and Practice of Breast Self-Examination among Mansoura University Female Students. Journal of American Science, 9, 253-261.

[36] Hackshaw, A. and Paul, E.A. (2003) Breast Self-Examination and Death from Breast Cancer: A Meta-Analysis. British Journal of Cancer, 88, 1047-1053. http://dx.doi.org/10.1038/sj.bjc.6600847

[37] Weiss, N.S. (2003) Breast Cancer Mortality in Relation to Clinical Breast Examination and Breast Self-Examination. The Breast Journal, 9, S86-S89. http://dx.doi.org/10.1046/j.1524-4741.9.s2.9.x

[38] Santora, L.M., Mahoney, M.C., Lawvere, S., Englert, J.J., Symons, A.B. and Mirand, A.L. (2003) Breast Cancer Screening Beliefs by Practice Location. BMC Public Health, 3, 9. http://dx.doi.org/10.1186/1471-2458-3-9

[39] Halbert, C.H., Kessler, L., Wileyto, E.P., Weathers, B., Stopfer, J., Domchek, S., et al. (2006) Breast Cancer Screening Behaviors among African American Women with a Strong Family History of Breast Cancer. Preventive Medicine, 43, 385-388. http://dx.doi.org/10.1016/j.ypmed.2006.06.003

[40] Austoker, J. (2003) Breast Self Examination: Does Not Prevent Deaths Due to Breast Cancer, but Breast Awareness Is 
Still Important. BMJ: British Medical Journal, 326, 1. http://dx.doi.org/10.1136/bmj.326.7379.1

[41] Karayurt, Ö., Özmen, D. and Çetinkaya, A.Ç. (2008) Awareness of Breast Cancer Risk Factors and Practice of Breast Self Examination among High School Students in Turkey. BMC Public Health, 8, 359. http://dx.doi.org/10.1186/1471-2458-8-359

[42] Tavafian, S.S., Hasani, L., Aghamolaei, T., Zare, S. and Gregory, D. (2009) Prediction of Breast Self-Examination in a Sample of Iranian Women: An Application of the Health Belief Model. BMC Women's Health, 9, 37. http://dx.doi.org/10.1186/1472-6874-9-37

[43] Budden, L. (1998) Registered Nurses' Breast Self-Examination Practice and Teaching to Female Clients. Journal of Community Health Nursing, 15, 101-112.

[44] Heidari, Z., Mahmoudzadeh-Sagheb, H. and Sakhavar, N. (2008) Breast Cancer Screening Knowledge and Practice among Women in Southeast of Iran. Acta Medica Iranica, 46, 321-328.

[45] Okobia, M.N., Bunker, C.H., Okonofua, F.E. and Osime, U. (2006) Knowledge, Attitude and Practice of Nigerian Women towards Breast Cancer: A Cross-Sectional Study. World Journal of Surgical Oncology, 4, 11. http://dx.doi.org/10.1186/1477-7819-4-11

[46] Oluwatosin, O.A. and Oladepo, O. (2006) Knowledge of Breast Cancer and Its Early Detection Measures among Rural Women in Akinyele Local Government Area, Ibadan, Nigeria. BMC Cancer, 6, 271. http://dx.doi.org/10.1186/1471-2407-6-271

[47] Raupach, J.C. and Hiller, J.E. (2002) Information and Support for Women Following the Primary Treatment of Breast Cancer. Health Expectations, 5, 289-301. http://dx.doi.org/10.1046/j.1369-6513.2002.00191.x

[48] Rees, C.E. and Bath, P.A. (2000) The Information Needs and Source Preferences of Women with Breast Cancer and Their Family Members: A Review of the Literature Published between 1988 and 1998. Journal of Advanced Nursing, 31, 833-841. http://dx.doi.org/10.1046/j.1365-2648.2000.01341.x

[49] Donmez, Y.C., Dolgun, E. and Yavuz, M. (2012) Breast Self-Examination Practices and the Effect of a Planned Training Program in Western Turkey. Asian Pacific Journal of Cancer Prevention, 13, 6159-6161. http://dx.doi.org/10.7314/APJCP.2012.13.12.6159

[50] Sarfo, L.A., Awuah-Peasah, D., Acheampong, E. and Asamoah, F. (2013) Knowledge, Attitude, and Practice of Self-Breast Examination among Female University Students at Presbyterian University College, Ghana. American Journal of Research Communication, 1, 395-404.

[51] Facione, N.C., Dodd, M.J., Holzemer, W. and Meleis, A.I. (1997) Helpseeking for Self-Discovered Breast Symptoms. Implications for Early Detection. Cancer Practice, 5, 220-227.

[52] Trask, P.C., Pahl, L. and Begeman, M. (2008) Breast Self-Examination in Long-Term Breast Cancer Survivors. Journal of Cancer Survivorship, 2, 243-252. http://dx.doi.org/10.1007/s11764-008-0066-x

[53] Jebbin, N. and Adotey, J. (2004) Attitudes to, Knowledge and Practice of Breast Self-Examination (BSE) in Port Harcourt. Nigerian Journal of Medicine: Journal of the National Association of Resident Doctors of Nigeria, 13, 166-170.

[54] Amasha, H.A.-R. (2013) Breast Self-Examination and Risk Factors of Breast Cancer: Awareness of Jordanian Nurses. Health Science Journal, 7, 303-314.

\section{Submit or recommend next manuscript to SCIRP and we will provide best service for you:}

Accepting pre-submission inquiries through Email, Facebook, Linkedin, Twitter, etc

A wide selection of journals (inclusive of 9 subjects, more than 200 journals)

Providing a 24-hour high-quality service

User-friendly online submission system

Fair and swift peer-review system

Efficient typesetting and proofreading procedure

Display of the result of downloads and visits, as well as the number of cited articles

Maximum dissemination of your research work

Submit your manuscript at: http://papersubmission.scirp.org/ 